\title{
KEPEMIMPINAN (LEADERSHIP) BERBASIS KARAKTER DALAM PENINGKATAN KUALITAS PENGELOLAAN PERGURUAN TINGGI
}

\author{
Hardi Mulyono \\ Fakultas Ekonomi \\ Universitas Muslim Nusantara Al Washliyah \\ hardisurbakti@gmail.com
}

\begin{abstract}
Abstrak
Pemimpin itu mempunyai sifat, kebiasaan, temperamen, watak dan kepribadian sendiri yang unik dan khas sehingga tingkah laku dan gayanya yang membedakan dirinya dari orang lain. Gaya atau style hidupnya ini pasti akan mewarnai perilaku dan tipe kepemimpinannya. Kepemimpinan merupakan kekuatan aspirasional, kekuatan semangat, dan kekuatan moral yang kreatif, yang mampu mempengaruhi para anggota untuk mengubah sikap, sehingga mereka searah dengan kemauan dan aspirasi pemimpin.Padahal semestinya pemimpin merupakan sosok yang menjadi teladan panutan bagi yang dipimpinnya. Beberapa tipe kepemimpinan secara umum adalah otokratik, kharismatik, laisser faire, demokratik, untuk melakukan perbaikan-perbaikan mutu. Tetapi kalau setiap kali dan dalam setiap hal harus memberi perintah atau pengarahan, akan menimbulkan kesulitan, karena setiap akan melakukan pekerjaan dengan baik itu harus dengan perintah pimpinan, dan kalau tidak ada perintah pimpinan tidak dilakukan pekerjaan dengan baik, maka perbaikan mutu kinerja yang terus menerus akan sulit diwujudkan. Seorang pemimpin memotivasi pengikut melalui gaya kepemimpinan yang berbasis Kearifan Lokal Indonesia yaitu gaya kepemimpinnan berbasis karakter dalam mewujudkan ini diperlukan saat ini gaya manajemen kepemimpinan yang mengintegrasikan 18 nilai-nilai charakter building ke dalam gaya kepimpinan pengelolaan PT sehinggga tercapai visi dan misi dari Perguruan Tinggi
\end{abstract}

Kata kunci: berbasis karakter, model kepemimpinan, peningkatan kualitas, perguruan tinggi, motivasi.

\begin{abstract}
The leader possesses his unique traits, habits, temperaments and personalities which distinguish his behavior and style from others. The style of his life will definitely influence the behavior and type of his leadership. Leadership is an aspirational force, a force of morale, and a creative moral force which is capable of impacting members to change their attitudes in order to be aligning with the leader's will and aspiration. In fact, a leader is supposed to be a role model for his people. Some types of leadership in general are autocratic, charismatic, laissez-faire, democratic which aim is to make quality improvements. Unfortunately, giving repeated orders or directions will create intricacy. This might happen as the subordinates will only act upon the leader's command and ignore the signals for quality improvement which eventually affects the working performances. Moreover, the targets and goals may not be achieved well. A leader can motivate his followers through a leadership style which based on Indonesian local wisdom. This is a character-based leadership style which can be realized by integrating eighteen values of character building into the leadership style particularly in the domain of Higher Education management. This is aimed to achieve the vision and mission of Higher Education.
\end{abstract}


Keywords: character-based, higher education, leadership model, motivation, quality enhancement.

\section{PENDAHULUAN}

\subsection{Latar Belakang Masalah}

Pemimpin itu mempunyai sifat, kebiasaan, temperamen, watak dan kepribadian sendiri yang unik dan khas sehingga tingkah laku dan gayanya yang membedakan dirinya dari orang lain. Gaya atau style hidupnya ini pasti akan mewarnai perilaku dan tipe kepemimpinannya. Kepemimpinan merupakan kekuatan aspirasional, kekuatan semangat, dan kekuatan moral yang kreatif, yang mampu mempengaruhi para anggota untuk mengubah sikap, sehingga mereka searah dengan kemauan dan aspirasi pemimpin. Padahal semestinya pemimpin merupakan sosok yang menjadi teladan panutan bagi yang dipimpinnya.

Kepemimpinan adalah proses mengarahkan dan mempengaruhi aktivitas-aktivitas tugas dari orangorang dalam kelompok. Kepemimpinan berarti melibatkan orang lain, yaitu bawahan atau karyawan yang dipimpin (Sunarto, 2005).

Menurut Kartono (2010), pemimpin itu mempunyai sifat, kebiasaan, temperamen, watak dan kepribadian sendiri yang unik khas sehingga tingkah laku dan gayanya yang membedakan dirinya dari orang lain. Gaya atau style hidupnya ini pasti akan mewarnai perilaku dan tipe kepemimpinannya. Sehingga dapat memunculkan beberapa tipe kepemimpinan. Misalnya tipe-tipe kharismatik, paternalistik, militeristik, otokratis, laissez faire, populis, administratif dan demokratis.

Dalam kenyataannya yang dihadapi dan permasalahan dari beberapa tife kepemimpinan ini memiliki kelemahan di dalam menjalankannya terutama di Perguruan Tinggi.Sebagaimana diketahui bahwa Pemimpin harus selalu dapat memotivasi anggota organisasi perguruan tinggi untuk melakukan perbaikan-perbaikan mutu. Tetapi kalau setiap kali dan dalam setiap hal harus memberi perintah atau pengarahan, itu akan menimbulkan kesulitan. Kalau setiap melakukan pekerjaan dengan baik itu harus dengan perintah pimpinan, dan kalau tidak ada perintah pimpinan tidak dilakukan pekerjaan dengan baik, maka perbaikan mutu kinerja yang terus menerus akan sulit diwujudkan. Oleh karena itu agar kepemimpinan itu selain untuk memberi pengarahan atau perintah tentang hal-hal yang perlu ditingkatkan mutunya, juga perlu digunakan untuk menumbuhkan motivasi intrinsik, yaitu menumbuhkan kesadaran akan perlunya setiap orang dalam perguruan tinggi itu selalu berupaya meningkatkan mutu kinerjanya masing-ma-sing secara individual maupun bersama-sama sebagai kelompok ataupun sebagai organisasi.

Sistem manajemen perguruan tinggi telah menjadi fokus kerja sama kelompok perguruan tinggi yang berada di satu kawasan, dengan pusat perhatian terhadap manajemen mutu/peningkatan mutu. Manajemen perguruan tinggi harus ditangani dalam bentuk suatu paradigma baru, atau kerangka berpikir baru dalam manajemen. Tujuan format manajemen baru ini adalah peningkatan kualitas secara berkelanjutan, dengan memasukkan 
asas otonomi sebagai daya gerak untuk membuat sistem lebih dinamis, akuntabilitas atau tanggungjawab agar otonomi terselenggara secara bertanggung jawab, akreditasi untuk menjamin mutu lulusan, dan evaluasi-diri agar proses pengambilan keputusan dalam perencanaan didasarkan atas data dan informasi yang empiris. Becermin kepada keberhasilan MC.Bride memimpin Miovision, gaya kepemimpinan (Leadership) memang menjadi salah satu faktor penting yang merupakan penentu . Kesuksesan organisasi dari gaya kepemimpinan berarti sikap dan pendekatan pemimpin dalam memberikan arahan, menerapkan rencana dan strategi dan memotivasi pengikutnya, situasi yang berbeda mensyaratkan gaya kepemimpinan yang berbeda.

Seorang pemimpin memotivasi pengikut melalui gaya kepemimpinan yang berbasis Kearifan Lokal Indonesia yaitu gaya kepemimpinnan berbasis karakterdalam mewujudkan ini diperlukan saat ini gaya manajemen kepemimpinan yang mengintegrasikan 18 nilai-nilai charakter building ke dalam gaya kepimpinan pengelolaan PT dilingkungan aw sehinggga tercapai visi dan misi dari Perguruan Tinggi tersebut. Tentu yang akan menghasilkan pencapaian tujuan kelompok dan tujuan individu. Pengikut yang termotivasi akan berusaha mencapai tujuan secara sukarela dan selanjutnya menghasilkan kepuasan. Kepuasan mengakibatkan kepada perilaku pencapaian tujuan yang diulang kembali untuk mencapai tujuan atau memenuhi kebutuhan di masa yang akan datang.

\subsection{Rumusan Masalah}

Bagaimanakah Pola Kepemimpinan Dalam Penegelolaan Perguruan Tinggi Yang Diintegrasikan dalam 18 Karakter Bangsa?

\section{METODE}

\subsection{Jenis Penelitian}

pendekatan yang dilakukan dengan cara menelaah teori-teori , konsep-konsep , asas-asas yang berkaitan dengan yang dibahas dalam tulisan ini.

\subsection{Sumber Data}

Bahan hukum yang diperoleh dari Data Sekunder yaitu bersumber dari Penelitian Kepustakaan (Library Research). 2.3 Teknik Pengumpulan Data Teknik yang digunakan dalam penelitian ini adalah teknik studi dokumen yaitu data yang diperoleh dari Kepustakaan yang relevan .

\subsection{Teknik Analisis}

Keseluruhan data yang telah didapat akan dianalisis secara Kualitatif atau dikenal dengan Analisis Deskriftif Kualitatif. Dimana keseluruhan data yang terkumpul akan dianalisis secara sistematis .

\section{HASIL DAN PEMBAHASAN}

Pemimpin dalam menentukan gaya kepemimpinannya harus mampu menyesuaikan dengan situasi, kondisi pada waktu dan tempat tertentu. Pemimpin-pemimpin yang berhasil adalah mereka yang bisa menyesuaikan perilaku dirinya sesuai dengan tuntutan dari keunikan lingkungannya. Kepemimpinan yang efektif atau tidak efektif itu sangat tergantung akan gaya perilaku yang disesuaikan dengan situasi tertentu (Grensing, 2008). 
Menurut Siagian (2008), ada 5 (lima) kategori gaya kepemimpinan yang dapat digunakan seorang pemimpin, yaitu:
a) Tipe Otokratik
b) Tipe Paternalistik.
c) Tipe Kharismatik.
d) Tipe Laissez-faire.
e) Tipe Demokratik.

$\begin{array}{crr}\text { Menurut } & \text { Kuswadi } & \text { dalam } \\ \text { Winardi (2004) } & \text { bahwa } & \text { gaya }\end{array}$ kepemimpinan yang kurang pas atau kurang cocok dilaksanakan pemimpin kepada pegawainya dapat menurunkan motivasi, kinerja dan akhirnya kepuasan kerja. Senada dengan itu Winardi (2004) mendefinisikan pemimpin adalah seseorang yang karena kecakapankecakapan pribadinya dengan atau tanpa pengangkatan resmi dapat mempengaruhi kelompok yang dipimpinnya untuk menggerakkan usaha bersama kearah pencapaian sasaran-sasaran tertentu. Secara garis besar, pendekatan atau perspektif tentang kepemimpinan terdiri dari:

\section{Teori Sifat (Trait Theory)}

Teori ini lebih menekankan pada aspek kepribadian seperti intelektualisasi, emosi, keadaan fisik (usia, tinggi dan berat badan) dan sifat-sifat pribadi lainnya. Teori ini memusatkan perhatiannya pada dua aspek perilaku kepemimpinan dan gayagaya kepemimpinan. Aspek pertama menekankan pada fungsifungsi yang dilakukan pemimpin dalam kelompoknya. Agar kelompok berjalan dengan efektif, seseorang harus melaksanakan dua fungsi utama, yaitu:

a) Fungsi-fungsi yang berhubungan dengan tugas (task related), atau pemecahan masalah, yang menyangkut pemberian saran penyelesaian, informasi dan pendapat.

b) Fungsi-fungsi pemeliharaan kelompok atau sosial, mencakup segala sesuatu yang dapat membantu kelompok berjalan lebih lancar, persetujuan dengan kelompok lain, penengahan perbedaan pendapat dan sebagainya.

Aspek kedua pendekatan perilaku kepemimpinan memusatkan pada gaya pemimpin dalam hubungannya dengan bawahan.

2. Teori Situasional (Contingency Theory)

Pendekatan

Situasionalkontingensi mengambarkan bahwa gaya yang digunakan tergantung pada faktor-faktor seperti situasi, tugas, organisasi dan variabelvariabel lingkungan lainnya. Teori-teori situasional yang terkenal adalah (a) Robert Tannenbaum dan Warren $\mathrm{H}$. Schmidt, (b) Fielder, (c) Hersey dan Blanchard, (d) Leader Member Exchange Theory, (e) Path Goal Theory, Participation Model.

\section{Teori Perilaku}

Mengambarkan perilaku spesifik membedakan pemimpin dan yang bukan pemimpin. Peneliti Ohio mengidentifikasikan terdapat dua kelompok prilaku yang mempengaruhi efektivitas kepemimpinan yaitu struktur inisiatif (initiating structure) dan pertimbangan (consideration). Faktor consideration menggambarkan hubungan yang sangat hangat antara seorang atasan dan bawahan, adanya saling percaya, kekeluargaan dan penghargaan terhadap gagasan bawahan. Struktur inisiatif menjelaskan bahwa seorang 
pemimpin itu mengatur dan menentukan pola organisasi, saluran komunikasi, struktur peran dalam pencapaian tujuan organisasi dan cara pelaksanaannya.

4.Teori Transformasional

Toeri kepemimpinan berkembang menuju kebanyak arah seperti kepemimpinan transformasional. Kepemimpinan transformasional adalah gaya yang digunakan bergantung pada faktor-faktor seperti situasi, karyawan, tugas, organisasi dan variabel-variabel lingkungan lainnya. Ada 4 (empat) unsur yang mendasari kepemimpinan transformasional yaitu:
a) Charisma
b) Inspiration
c) Intelectual Stimulatio
d) Individualized Consideration

Di dalam pola kepemimpinan yang dijelaskan di atas selalu mengalami kendala dan kelemahan di dalam prakteknya.Dan pada umumnya yang tercermin bahwa pemimpin itu adalah hal yang sangat di takuti dan ada gap .Sehingga keadaaannya menjadi tidak tercipta rasa kekeluargaan yang membuat suasana kerja menjadi tidak nyaman. Untuk mengatasi permasalahan-permasalahan ini diperlukan dikembangkan suatu model kepemimpinan yaitu "“ Berbasis Karakter". Ada 18 (delapan belas) nilai karakter bangsa sebagaimana yang dikeluarkan oleh Kemediknas yaitu:

1. Nilai Religius

2. Kejujuran

3. Toleransi

4. Disiplin
5. Kerja Keras

6. Kreatif

7. Mandiri

8. Demokratis

9. Rasa Ingin Tahu

10. Semangat Kebangsaan

11. Cinta Tanah Air

12. Menghargai Prestasi

13. Bersahabat/Komunikatif

14. Cinta Damai

15. Gemar Membaca

16. Peduli Lingkungan

17. Peduli Sosial

18. Tanggung Jawab.

Pengertian 18 nilai nilai karakter tersebut di atas adalah sebagai berikut :

\section{Religius}

Sikap dan perilaku yang patuh dalam melaksanakan ajaran agama yang dianutnya, toleran terhadap pelaksanaan ibadah agama lain, dan hidup rukun dengan pemeluk agama lain.

\section{Jujur}

Perilaku yang didasarkan pada upaya menjadikan dirinya sebagai orang yang selalu dapat dipercaya dalam perkataan, tindakan, dan pekerjaan.

\section{Toleransi}

Sikap dan tindakan yang menghargai perbedaan agama, suku, etnis, pendapat, sikap, dan tindakan orang lain yang berbeda dari dirinya.

\section{Disiplin}

Tindakan yang menunjukkan perilaku tertib dan patuh pada berbagai ketentuan dan peraturan.

\section{Kerja Keras}

Tindakan yang menunjukkan perilaku tertib dan patuh pada berbagai ketentuan dan peraturan. 


\section{Kreatif}

Berpikir dan melakukan sesuatu untuk menghasilkan cara atau hasil baru dari sesuatu yang telah dimiliki.

\section{Mandiri}

Sikap dan perilaku yang tidak mudah tergantung pada orang lain dalam menyelesaikan tugastugas.

\section{Demokratis}

Cara berfikir, bersikap, dan bertindak yang menilai sama hak dan kewajiban dirinya dan orang lain.

\section{Rasa Ingin Tahu}

Sikap dan tindakan yang selalu berupaya untuk mengetahui lebih mendalam dan meluas dari sesuatu yang dipelajarinya, dilihat, dan didengar.

10. Semangat Kebangsaan

Cara berpikir, bertindak, dan berwawasan yang menempatkan kepentingan bangsa dan negara di atas kepentingan diri dan kelompoknya.

11. Cinta Tanah Air

Cara berpikir, bertindak, dan berwawasan yang menempatkan kepentingan bangsa dan negara di atas kepentingan diri dan kelompoknya.

12. Menghargai Prestasi

Sikap dan tindakan yang mendorong dirinya untuk menghasilkan sesuatu yang berguna bagi masyarakat, dan mengakui, serta menghormati keberhasilan orang lain.

13. Bersahabat/Komunikatif

Sikap dan tindakan yang mendorong dirinya untuk menghasilkan sesuatu yang berguna bagi masyarakat, dan mengakui, serta menghormati keberhasilan orang lain.

\section{Cinta Damai}

Sikap dan tindakan yang mendorong dirinya untuk menghasilkan sesuatu yang berguna bagi masyarakat, dan mengakui, serta menghormati keberhasilan orang lain.

\section{Gemar Membaca}

Kebiasaan menyediakan waktu untuk membaca berbagai bacaan yang memberikan kebajikan bagi dirinya.

16. Peduli Lingkungan

Sikap dan tindakan yang selalu berupaya mencegah kerusakan pada lingkungan alam di sekitarnya, dan mengembangkan upaya-upaya untuk memperbaiki kerusakan alam yang sudah terjadi.

\section{Peduli Sosial}

Sikap dan tindakan yang selalu ingin memberi bantuan pada orang lain dan masyarakat yang membutuhkan.

\section{Tanggung Jawab}

Sikap dan perilaku seseorang untuk melaksanakan tugas dan kewajibannya, yang seharusnya dia lakukan, terhadap diri sendiri, masyarakat, lingkungan (alam, sosial dan budaya), negara dan Tuhan Yang Maha Esa.

Diantara 18 nilai nilai karakter bangsa tersebut yang dapat diimplementasi kan dalam pola kepemimpinan untuk menjalankan usaha dalam upaya menghindari kejahatan Cyber Crime Dalam Persaingan Bisnis adalah sebagai berikut :

1. Nilai kejujuran.

Menurut Sugono kata jujur dapat didefinisikan sebagai lurus hati, tidak berbohong, dan tidak curang. Jujur adalah salah satu sifat yang sangat penting bagi kehidupan. 
2. Nilai Kemandirian.

3. Nilai Kedisiplinan.

Menurut Sugono definisi kata disiplin adalah ketaatan (kepatuhan) kepada peraturan. Nilai kedisiplinan dapat diwujudkan antara lain dalam bentuk kemampuan mengatur waktu dengan baik, kepatuhan pada seluruh peraturan dan ketentuanyang berlaku , mengerjakan segala sesuatunya tepat waktu, dan fokus pada pekerjaan.

4. Nilai Tanggung Jawab.

Menurut Sugono, definisi kata tanggung jawab adalah keadaan wajib menanggung segala sesuatunya (kalau terjadi apa apa boleh dituntut, dipersalahkan dan diperkarakan)

Tanggung Jawab adalah menerima segala sesuatu dari sebuah perbuatan yang salah, baik itu disengaja atau tidak disengaja. Tanggung Jawab tersebut berupa perwujudan kesadaran akan kewajiban menerima dan menyelesaikan semua masalah yang telah di lakukan. Tanggung jawab juga merupakan suatu pengabdian dan pengorbanan maksudnya pengabdian adalah perbuatan baik yang berupa pikiran , pendapat ataupun tenaga sebagai perwujudandari sem kesetiaan, cita kasih sayang, norma, atau satu ikatan dari semua itu dilakukan dengan ikhlas.

5. Nilai Kerja Keras.

Bekerja keras didasari dengan adanya kemauan. Kata "kemauan" menimbulkan asosiasi dengan ketekadan, ketekunan, daya tahan, tujuan jelas, daya kerja, pendirian, pengendalian diri, keberanian, keteguhan, tenaga, kekuatan, kelaki-lakian dan pantang mundur.

6. Nilai Keadilan.

Berdasarkan arti katanya, adil adalah sama berat, tidak berat sebelah, tidak memihak. Di dalam kehidupan sehari-hari, pemikiran pemikiran sebagai dasar pertimbangan untuk menghasilkan keputusan akan terus berkembang seiring dengan pengalaman dan pengetahuan yang dimiliki seseorang.

Apabila seorang Pemimpin di Perguruan Tinggi di dalam pengelolaannya membuat suatu pola kepemimpinan yang 18 tersebut di terapkan adalah merupakan suatu terobosan teknologi yang terbaru yang selama ini diabaikan walaupun sebenarnya bukanlah merupakan yang baru karena memang sudah merupakan konsep ajaran agama dan budaya yang dianut, namun kenyataannya tidak dianggap namun mengadopsi gaya kepemimpinan pola dari Barat dan dianggap trend yang ternyata belum tentu cocok dengan budaya yang ada di masyarakat kita.

\section{KESIMPULAN}

Inovasi manajemen kepemimpinan dalam Pengelolaan Perguruan Tinggi diintegrasikan yang di dalam nilai nilai 18 karakter bangsa merupakan konsep ajaran agama dan budaya yang dianut, namun kenyataannya trendnya mengadopsi gaya kepemimpinan pola dari Barat yang ternyata belum tentu cocok dengan budaya yang ada di masyarakat kita.

\section{DAFTAR PUSTAKA}

Damiyati Zuchdi,2013,Model
Pendidikan
Perpustakaan Nasional.


Moleong, 2005, Metodologi

Penelitian Kualitatif, PT.

Remaja Rosdakarya Bandung.

Muchlas Samani,2011,Konsep Dan

Model

Pendidikan

Karakter,PT.Remaja

Rosdakarya. 